\title{
JOGNN CLINICAL STUDIES
}

\section{Continence for Women: \\ A Test of AWHONN's Evidence- Based Protocol in Clinical Practice}

Carolyn M. Sampselle, RNC, PhD, FAAN, Jean F. Wyman, RN, PhD, FAAN, Karen Kelly Thomas, RNC, PhD, Diane K. Newman, RNC, MSN, CRNP, FAAN, Mikel Gray, CUNP, CCCN, PhD, FAAN, Molly Dougherty, RN, PhD, FAAN, Patricia A. Burns, NP, PhD, FAAN

Objective: To test the effectiveness of an evidence-based protocol for urinary incontinence in increasing identification of women with the condition and improving their outcomes. study.

Design: Prospective formative evaluation

Setting: Twenty-one public, private, and other women's health care sites.

Participants: Women in ambulatory care settings $(N=1,474)$ provided descriptive statistics. Clinical outcomes were tested in 132 cases for whom pre- and posttreatment data were available.

Interventions: Standardized screening and baseline follow-up forms were used to minimize time burden on clinicians; bladder and pelvic floor muscle training materials were provided to clinicians for distribution.

Main Outcome Measures: Self-reported frequency, volume, and quality of life related to incontinence and cost of self-management were used to assess protocol effectiveness.

Results: Frequency of incontinence episodes, estimated volume lost per episode, and the cost of self-management decreased. Quality of life improved, as reflected in decreased bother attributed to incontinence and in the number of women avoiding activities such as shopping, exercising, or travel because of incontinence.

Conclusions: This simple program of pelvic floor muscle and bladder training, as it has been systematically implemented in a variety of ambulatory women's health care settings, has benefited women's continence status. The results of this project strongly support widespread application. JOGNN 29, 18-26; 2000.

Keywords: Bladder training-ContinencePelvic floor-Pelvic muscle-Urinary incontinence

Accepted: September 1999

Involuntary leakage of urine or urinary incontinence affects, on average, $25-34 \%$ of women living at home (Thom, 1998). Such women comprise the population from which the caseloads of most ambulatory care centers are drawn. The proportion of women affected with urinary incontinence is increased by age and parity. In the perimenopausal years symptoms increase, with $31 \%$ of women reporting at least one incontinence episode per month (Burgio, Matthews, \& Engel, 1991). Lagace, Hanson, and Hickner (1993) documented increases in overall incontinence and in more severe or bothersome levels of involuntary leakage among women in their $40 \mathrm{~s}$ and $50 \mathrm{~s}$. In a respected study of carefully sampled women, $38 \%$ age 60 years and older who were living at home reported symptoms of urinary incontinence (Diokno, Brock, Brown, \& Herzog, 1986). Vaginal birth also is associated with greater prevalence of incontinence. Women who have had even one vaginal birth are more than 2.5 times as likely to report incontinence than are their nulliparous counterparts (Jolleys, 1988; Sommer et al., 1990), and the rate of incon- 
tinence increases with parity (Nygaard, DeLancey, Arnsdorf, \& Murphy, 1990). Urinary incontinence is clearly a condition that affects the lives of many women and thus is of concern to the nurses who provide their health care.

Recognizing the widespread impact of urinary incontinence on the health and well-being of women, the Association of Women's Health, Obstetric and Neonatal Nurses (AWHONN) designated its third organizationally supported research utilization project to focus on this condition. That 3-year project, begun in 1995, consisted of three phases: Phase I, Planning, included the development of an evidence-based protocol which has been presented in detail in a previous publication (Sampselle et al., 1997), as well as the development of data management forms and the plan for implementation of the project; Phase II, Implementation, entailed site recruitment, training of nurses to use the evidence-based protocol, and data collection; and Phase III, Evaluation, involved assessment of the success of the process that enabled clinicians to use the protocol. These phases are discussed

\section{An evidence-based protocol for urinary incontinence was successfully implemented by clinicians in ordinary women's health ambulatory-care settings.}

in detail in the article immediately preceding this report (Sampselle et al., 2000, pp. 9-17). The information presented here is a report of the impact of the evidencebased protocol on nursing practice and on patient outcomes. The aim of the current study was to test the effectiveness of an evidence-based protocol for urinary incontinence in increasing identification of women with the condition and improving their outcomes.

\section{Hypotheses}

The project investigated two broad research questions: (a) Will change occur in clinical practice after clinicians are trained to identify urinary incontinence and to intervene using an evidence-based protocol? and (b) Will patient outcomes be positively affected after the protocol is instituted in the clinical setting? Six hypotheses based on these questions were tested.

The following hypothesis related to practice change:

1. More women will screen positive for urinary incontinence when routine screening is imple- mented as compared to the proportion who disclose the condition as reported in the literature.

The following hypotheses related to patient outcomes:

2. Urinary incontinence episodes will decrease in frequency.

3. Urine loss per episode will decrease in volume.

4. The cost of self-management of urinary incontinence will decrease.

5. The amount of bother associated with incontinence will decrease.

6. The number of activities avoided because of incontinence will decrease.

\section{Methods}

The initial sample consisted of 1,474 women screened for incontinence as a part of the routine history collected in their respective ambulatory settings. The screening questions were the following: Do you ever leak urine/water when you don't want to? Do you ever leak urine/water when you cough, laugh, or exercise? Do you ever leak urine/water on the way to use the bathroom? Do you ever use pads, tissue, or cloth in your underwear to catch urine? Of the total sample screened, $57 \%(842)$ responded "always" or "sometimes" on at least one of the four screening items.

Because the screening and the behavioral interventions of the evidence-based protocol are considered to be standard of care practice (Fantl et al., 1996) institutional review board approval was not required, although some participating sites obtained it. The women's willingness to complete the initial forms and to engage in the behavioral interventions presented by the clinicians constituted implied consent.

The number of women who provided feedback at the 4-month follow-up ( $n=132$ ) was markedly reduced from the original number who screened positive $(n=$ 842). Comparisons of selected baseline characteristics of the original and enduring longitudinal sample are presented in Table 1.

Differences between the two groups were apparent. Older women were more likely to persist with therapy; the mean age for those retained to the 4-month follow-up was 51 years as compared to 40 for the group who originally screened positive. White women were more likely to continue to the 4-month follow-up than were black or Latina women. Women who reported a lower duration of incontinence ( 25 months) were less likely to persist with treatment than those who reported a longer duration (39 months). Those who were experiencing a greater number of incontinence episodes per week were more likely to continue to the 4-month point. Thus, greater severity was associated with persistence in treatment. 


\section{TABLE 1}

\section{Comparison of Baseline Characteristics Between \\ Original and Enduring Longitudinal Sample}

Age
Racial
distribution $\quad$ African American
of three
major groups White
Duration of incontinence
Frequency of incontinence
Voiding frequency while awake
Nocturia frequency

$\begin{array}{ccc}\begin{array}{c}\text { Time 1 } \\ \text { Data Only } \\ (\mathbf{n}=842)\end{array} & \begin{array}{c}\text { Retained } \\ \text { to Time } \\ (\mathbf{n}=132)\end{array} & \begin{array}{c}\text { Statistical } \\ \text { Difference }\end{array} \\ 39.9 \text { Years } & 51.1 \text { Years } & \mathbf{p}<.001 \\ 18 \% & 7 \% & \\ 10 \% & 5 \% & p<.001 \\ & & \\ 72 \% & 88 \% & \\ & & \\ 24.6 \text { months } & 39.3 \text { months } & p<.0001 \\ 2.1 / \text { week } & 3.0 / \text { week } & p<.002 \\ 5.9 / \text { day } & 6.2 / \text { day } & n s \\ 1.8 / \text { night } & 1.3 / \text { night } & n s\end{array}$

The specific measures identified for each variable of interest and the analyses selected to test each hypothesis are detailed below:

Hypothesis 1. More women will screen positive for urinary incontinence (and will subsequently receive the recommended basic evaluation) when routine screening is implemented as compared to that proportion of women reported in the literature who disclose the condition. The proportion of women who responded positively to one or more of the four screening questions was compared to the percentage $(38-41 \%)$ of women identified by survey (Burgio, Ives, Locher, \& Arena, 1994; Goldstein, Hawthorne, Engeberg, McDowell, \& Burgio, 1992) who indicated that they had incontinence and had discussed the problem with a health care provider. Then, using the aggregate number of women reported by participating sites who answered any of the first four screening questions positively as the denominator, the proportion who completed the basic evaluation was calculated.

Hypothesis 2. Urinary incontinence episodes will decrease in frequency. Respondents indicated the frequency of urine lost during a typical week by selecting one of five categories (Item 2 on the basic evaluation, which is presented in Figure 1). Differences in the usual frequency of incontinence per week were determined by comparing the category selected on the basic evaluation with the category selected for item 2 on the ongoing evaluation (see Figure 2).

Hypothesis 3. Urine loss per episode will decrease in volume. Differences in amount of urine loss per episode were assessed by comparison of baseline indications of a selected category that estimated the volume of urine lost, on average, per episode of incontinence (Item 3) on the basic evaluation with the same item on the ongoing evaluation.

Hypothesis 4. The cost of self-management of urinary incontinence will decrease. A cost estimate was calculated by obtaining retail prices of all levels of protection, from panty liners to absorbent pants/super pads in two regional areas (Washington, DC, and Arizona). The mean cost of each type of protection was multiplied times the number of reported changes per day (as reported in Item 5) and then multiplied by seven to derive an estimated cost per week. These estimates were compared between the basic and the ongoing evaluations.

Hypothesis 5. The amount of bother associated with incontinence will decrease. Difference in level of bother (Item 4) was compared between the basic evaluation and the ongoing evaluation.

Hypothesis 6. The number of activities avoided because of incontinence will decrease. The percentage of women avoiding activities such as shopping, exercising, and traveling (Item 7) was compared between the basic evaluation and the ongoing evaluation.

\section{Analysis}

The statistical analyses were performed using the Statistical Package for the Social Sciences (Norusis, 1994). Chi square, $t$ test, and repeated measures analysis of variance were used for assessment of group differences in demographic characteristics and for hypothesis testing. Descriptive statistics were generated from the 1,474 cases initially screened across the 21 participating sites. To conduct hypothesis testing of effects on 


\section{Continence for Women Project: Basic Evaluation}

1. How long have you had the problem of leaking when you don't want to? months years

2. On average, how often do you lose urine/water during a typical week?

3. How would you describe the amount

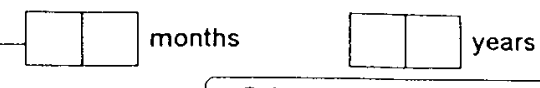

$O$ Less than once a week Once a week

More than once a week

Once a day

More than once a day

$$
\text { of urine you usually leak? }
$$

4. How much does this leakage bother you?

$\begin{array}{llllll}\text { Not at all } & \mathrm{O}_{1} & \mathrm{O}_{2} & \mathrm{O}_{3} & \mathrm{O}_{4} & \mathrm{O}_{5} \text { Very Much }\end{array}$

5. Are you currently using pads for protection against urine leakage?
ONo
Skip to \#6
O Yes

last week did 6. How many days last week did
you leak urine?

\begin{tabular}{|l|} 
What type? \\
\begin{tabular}{|l|} 
O Panty liner \\
O Sanitary pad \\
O Larger pad \\
O Absorbent pant
\end{tabular} \\
\hline
\end{tabular}

How many times per day do you need to change pads?

7. Are you avoiding certain activities because of a urine/water loss problem?

ONo Skip to \#8

OYes

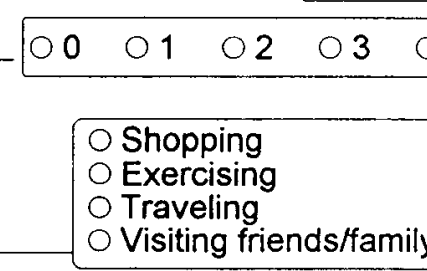

\begin{tabular}{|ll|}
\hline 01 or fewer & 04 \\
02 & 05 \\
03 & 06 or more \\
\hline
\end{tabular}

8. On average, how many times do you urinate/pass water during the day?

\begin{tabular}{|l|l}
\hline \\
\hline
\end{tabular}

\section{.}

9. Are you having burning or discomfort when you urinate/pass water?

night?
O Dating
O Having sex
Dancing
O Playing sports

10. Do you have a history of: (check as many as apply)
Diabetes
O Constipation
O Stroke
O Problems walking
Multiple Sclerosis
O Spinal cord injury
Previous treatment or surgery

11. Do you feel that your bladder is empty after you urinate/pass water? OYes

O No

12. Do you ever push down or strain to urinate/pass water?

OYes ONo

13. Please list any medications that you are currently taking, either prescribed or purchased over the counter.
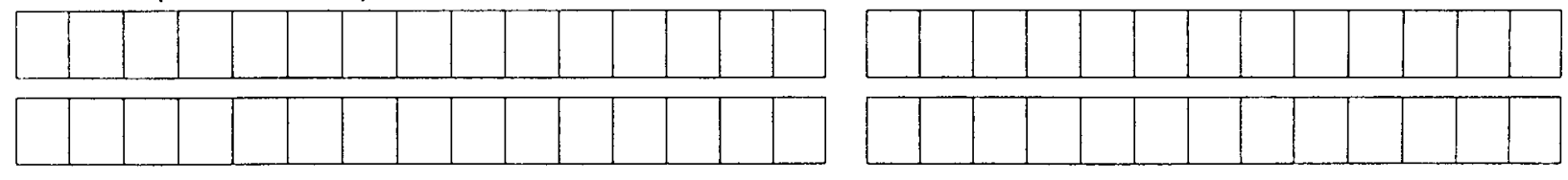

14. Who completed this form? OMyself ONurse OSomeone else

Copyright 1997 AWHONN RU3-B

\section{The nurse will talk with you about plans for follow-up.}


Date:
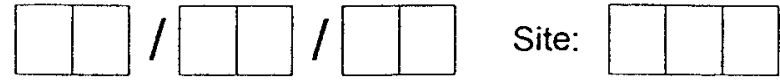

Participant

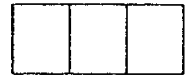

\section{Continence for Women Project: Ongoing Evaluation}

1. On average, how often do you lose urine/water during a typical week?

$\bigcirc$ Less than once a week

Once a week

More than once a week

Once a day

$O$ More than once a day

2. How would you describe the amount of urine you usually leak?

3. How many days last week did you leak urine?

$\begin{array}{lllllllll}0 & 01 & 02 & 03 & 04 & 05 & 06 & 07\end{array}$

4. How much does this leakage bother you?

$\begin{array}{lllll}\text { Not at all } O 1 & \bigcirc 2 & 03 & 04 & \bigcirc 5 \text { Very Much }\end{array}$

5. Are you currently using pads for protection against urine leakage?
No
Skip to \#6

O Yes
What type?

Panty liner

$O$ Sanitary pad

$O$ Larger pad

Absorbent pant
How many times per day do you need to change pads?

\begin{tabular}{|ll|}
\hline 01 or fewer & 04 \\
02 & 05 \\
03 & 06 or more
\end{tabular}

6. Are you avoiding certain activities because of a urine/water loss problem?
ONo
Skip to \#7 Skip to \#7

OYes

O Shopping

O Exercising

O Traveling

O Visiting friends/family
O Dating

O Having sex

O Dancing

O Playing sports

7. On average, how many times do you urinate/pass water during the day?

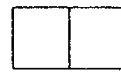

night?

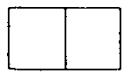

8. Do you want additional treatment such as: 
typical caseloads of ambulatory women, $57 \%$ screened positive for urinary incontinence. Nearly $25 \%$ of the incontinent women experienced episodes every day.

continence status, we analyzed only the 132 cases for whom baseline (pretreatment) and 4 month (posttreatment) data were available. Differences were examined between women who finished treatment and those who dropped out. The alpha level of .05 was set to judge the significance of demonstrated differences.

\section{Results}

\section{Factors Associated with Incontinence}

The initial sample $(N=1,474)$ was divided into those who reported incontinence and those who did not. The two groups were compared on selected demographic characteristics (see Table 2). Age, race, vaginal birth, and history of hysterectomy were significantly different between the continent and incontinent groups. As expected, no differences were found between groups with regard to educational level.

\section{Pretreatment Continence Status}

The pretreatment level of incontinence severity is reflected in the distributions presented in Table 3. Nearly $25 \%$ of those who were incontinent reported unwanted urine loss occurring once or more a day.

When asked about use of protective pads, $37 \%$ of those reporting incontinence indicated that they required this protection, with nearly $42 \%$ having to change at least twice a day.

The results presented in the following paragraphs detail the outcome of the hypothesis-testing process and constitute the actual evaluation of the protocol itself. They demonstrate its effectiveness when carried out by typical providers in ordinary clinical settings as opposed to the more systematic and controlled environment in which conventional research is conducted.

\section{Nursing Practice Outcomes}

Hypothesis 1 tested for an increase in the percentage of incontinent women identified by routine screening in a clinical setting as compared to those who reported seeking help as documented by previous research. Population-based surveys have found that the percentage of incontinent individuals who actually report their condition to a health care provider ranges from $38 \%$ to $41 \%$ (Burgio et al., 1994; Goldstein et al.,

\section{After the intervention women reported decreased incontinence frequency, volume, and cost of self- management, and fewer women avoided activities because of incontinence.}

\section{TABLE 2}

Factors Associated With Urinary Incontinence

\begin{tabular}{|c|c|c|c|c|}
\hline Variable & $\begin{array}{l}\text { Continent } \\
(\mathrm{n}=6.32)\end{array}$ & $\begin{array}{l}\text { Incontinent } \\
(\mathrm{n}=842)\end{array}$ & For $X^{2}$ & p \\
\hline Race & & & $19.0^{\mathrm{b}}$ & .0001 \\
\hline African American & $50.4 \%$ & $49.6 \%$ & & \\
\hline Latina & $49.3 \%$ & $50.7 \%$ & & \\
\hline White & $38.8 \%$ & $63.2 \%$ & & \\
\hline Age (Mean years) & $35 \pm 15$ & $44 \pm 16$ & $117.2^{\mathrm{a}}$ & .0001 \\
\hline Ever having given birth & $64.9 \%$ & $82.0 \%$ & $53.3^{\mathrm{a}}$ & .0001 \\
\hline Vaginal birth (Mean) & $1.1 \pm 1.4$ & $1.8 \pm 1.5$ & $90.6^{\mathrm{a}}$ & .0001 \\
\hline Hysterectomy & $0.1 \%$ & $19.5 \%$ & $32.8^{\mathrm{a}}$ & 0001 \\
\hline
\end{tabular}




\begin{tabular}{|c|c|c|c|c|c|}
\hline \multirow[t]{2}{*}{ Frequency of leaking } & $<1 /$ wk & $1 / w k$ & $>1 / w k$ & $1 /$ day & $>1 /$ day \\
\hline & 43.1 & 10.5 & 21.7 & 9.5 & 15.2 \\
\hline \multirow[t]{2}{*}{ Average amount lost } & Damp & Wet & Cupful & Flood & \\
\hline & 61.5 & 33.3 & 3.2 & 2.0 & \\
\hline \multirow[t]{2}{*}{$\begin{array}{l}\text { Amount bothered } \\
\text { by leakage }\end{array}$} & $\begin{array}{c}1 \\
\text { (Not At All) }\end{array}$ & 2 & 3 & 4 & $\begin{array}{c}5 \\
\text { (Very Much) }\end{array}$ \\
\hline & 20.8 & 23.1 & 15.1 & 12.9 & 28.1 \\
\hline
\end{tabular}

1992). By comparison, $57 \%(842 / 1,474)$ of patients were identified as incontinent with the routine screening used in the current project. This represents a marked increase when measured against that reported in the literature. In addition to identifying the condition, $63 \%$ $(529 / 842)$ of women who answered affirmatively on one or more of the screening questions completed a basic evaluation and nearly $78 \%(653 / 842)$ of them provided partial information on the basic evaluation. This evidence supports Hypothesis 1, demonstrating that, among ambulatory clinic patients, routine screening and requested completion of basic evaluation information results in identification of a higher prevalence of incontinence as compared to the proportion of women who typically initiate discussion of incontinence with a health care provider.

\section{Patient Outcomes}

The outcome measures of frequency of incontinence episodes, volume of leakage per episode, cost of self-management, and quality of life showed improve- ment from baseline (Time 1) to the 4-month posttreatment point (Time 3) (see Table 4).

Hypothesis 2, decreased frequency of episodes of incontinence, was supported by change in the predicted direction. Women experienced significantly fewer episodes in a typical week and in the number of days of leaking in the past week. Hypothesis 3, decreased volume of leakage per incontinent episode, was supported. Women selected lower categories to reflect the extent of leakage per incontinence episode over the time of treatment. Hypothesis 4, decreased cost of self-management, Hypothesis 5, decreased amount of bother associated with incontinence, and Hypothesis 6, decreased activities avoided due to incontinence, also were supported. All indices specified by the hypotheses significantly declined from baseline to posttreatment.

\section{Discussion}

These results demonstrate the effectiveness of the evidence-based protocol in actual clinical settings. The

\section{TABLE 4}

Changes in Continence Status Pre- and Posttreatment Among Women Who Reported Urinary Incontinence

Mcasurc
Leakage in a typical week
Number of days of leakage past week
Average volume of urine lost
Micturition frequency during the day
Frequency during the night
Cost of self-management
Bother score
Percentage avoiding activities

$\begin{gathered}\text { Pretreatment } \\ (\mathbf{n}=132)\end{gathered}$
3.0
2.9
1.6
6.1
1.7
$\$ 1.18$
3.1
$14.0 \%$

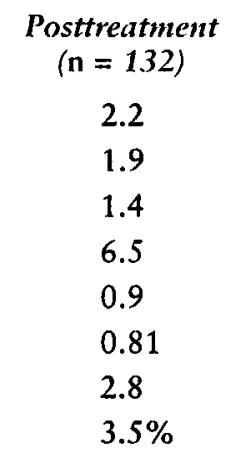

$\begin{array}{cl}F & p \\ 7.2 & .002 \\ 10.2 & .0001 \\ 4.6 & .03 \\ 1.4 & n s \\ 5.9 & .012 \\ 5.75 & .031 \\ 12.31 & .0001 \\ 7.96 & .001\end{array}$

"Actual volume was not measured. Respondents indicated 1 of 4 categories ranging from a few drops to soaking outer clothes. 
participating sites represented a wide range of practice settings, and the overall sample was reasonably diverse as reported in the immediately preceeding article (Sampselle et al., 2000). This supports an acceptable level of generalizability and warrants the implementation of the protocol in general ambulatory women's health care settings.

\section{Nursing Practice Outcomes}

It should be noted that the reported proportion of women who screened positive for urinary incontinence and subsequently underwent a complete basic evaluation $(63 \%)$ is artificially low. At least 124 additional basic evaluations were completed, but were inadequately identified. That is, the basic evaluation had been completed, but it was not possible to link them accurately to a specific set of screening questions. Because a woman was to complete the basic evaluation only if her responses to screening questions indicated an incontinence problem, a less conservative estimate of follow-up would be $78 \%$ (653/842). Either proportion is substantially greater than that reflected in previous surveys. This finding suggests that routine screening, coupled with a system that facilitates follow-up for basic evaluation, is effective in identifying symptomatic individuals. Thus, even more important than the systematic data management framework that was introduced by the use of the teleform technology was the ease with which the screening and basic evaluation could be conducted. Whether or not computerized scanning is used, the standardized forms address the problem of how to carve out the time needed to conduct systematic routine screening and the recommended basic evaluation of those who screened positive for incontinence. The simple educational materials described in the earlier publication (Sampselle et al., 1997) could then be used to provide information about bladder and pelvic floor muscle training.

\section{Patient Outcomes}

The frequency, volume, and life impact of urinary incontinence decreased following treatment. Given that $57 \%$ of the baseline (Time 1) sample of women screened reported some problem with unwanted leakage, replication of this protocol in a wide range of ambulatory sites is likely to benefit diverse types of women across the lifespan.

It is noteworthy that those who were retained to the posttreatment point initially had more severe levels of incontinence as reflected in longer duration and greater frequency of involuntary loss prior to treatment. Others have reported that only $25 \%$ of incontinent women start treatment when it is offered (Samuelsson, Victor, \& Tibblin, 1997). Perhaps the severity of the condition motivates women to accept and persist with behavioral therapy.
Though it was not originally hypothesized, an additional benefit to women's overall well-being was noted. There was a decrease in the frequency of nocturia experienced by women posttreatment. While nocturia is clearly not incontinence, it disrupts sleep and can affect overall well-being. As can be seen in Table 4, the frequency of nocturia declined from a pretreatment level of 1.7 to a posttreatment frequency of $.9(F=5.9$, $p=.012)$. This phenomenon has not been reported previously and deserves further investigation.

The statistics and the hypothesis testing tell only part of the story. Anecdotal evidence contributed by site coordinators provides powerful insights into the impact of the protocol on the lives of individual women. One nurse told of a patient who offered to pay her own way to the AWHONN Convention so that she could explain to other women's health nurses how important the program was. "You changed my life!" she told the nurse who had implemented the protocol, "I want other nurses to know about this." Another woman whose voiding frequency decreased from about 15 to 8 times in the course of a 24-hour period, asked of the nurse who helped her, "Why haven't I heard about this before now?"

\section{Implications for Nursing Practice}

The results of this study demonstrate clear benefits to the health of women when this protocol is incorporated into standard ambulatory patient care. The four recommended screening questions will identify higher numbers of women at risk than will a less systematic approach. Given the significantly greater risk of women who have had a hysterectomy, nurses should be particularly vigilant when assessing this group.

The basic evaluation questions allow determination of which candidates will benefit more from referral, such as for treatment of neurologic disease, and those who should receive information about the value of bladder and pelvic floor muscle training. Information about available patient education materials and their incorporation into typical practice settings is discussed in detail (Sampselle et al., 1997), and updates are available at the AHCPR web-site

\section{http://www.hcfa.gov/medicaid/siq/siqipg.htm.}

Further research is in progress at the University of Michigan to assess the potential of the recommended behavioral intervention for the prevention of urinary incontinence. Given the very high attrition rates for African American and Latina women, further research is warranted to identify more effective implementation of the protocol for these groups. This will require the development and testing of culturally appropriate materials as well as translation into Spanish. 
In summary, this evidence-based protocol, as it has been systematically implemented in a variety of ambulatory women's health care settings, facilitated systematic screening and obtaining of baseline evaluation data. The simple program of pelvic floor muscle and bladder training yielded significant improvements in women's continence status. The results of this project support widespread incorporation of the protocol into clinical practice in ambulatory care sites.

\section{REFERENCES}

Burgio, K. L., Ives, D. G., Locher, J. L., \& Arena, V.C. (1994). Treatment seeking for urinary incontinence in adults. Journal of the American Geriatric Society, 42(2), 208-212.

Burgio, K. L., Matthews, K. A., \& Engel, B T. (1991). Prevalence, incidence and correlates of urinary incontinence in healthy, middle-aged women. Journal of Urology, 146, 1255-1259.

Diokno, A. C., Brock, B. M., Brown, H. B., \& Herzog, A. R. (1986). Prevalence of urinary incontinence and other urologic symptoms in the non-institutionalized elderly. Journal of Urology, 136, 1022-1025.

Fantl, J. A., Newman, D. K., Colling, J., DeLancey, J. O. L., Keeys, C., Loughery, R., McDowell, B. J., Norton, P., Ouslander, J., Schnelle, J., Staskin, D., Tries, J., Urich, V., Vitousek, S. H., Weiss, B. D., \& Whitmore, K. (1996). Urinary incontinence in adults: Acute of chronic management. (Clinical Practice Guideline, No. 2, 1996 Update, AHCPR Publication No. 96-0682). Rockville, MD: U.S. Department of Health and Human Services.

Goldstein, M., Hawthorne, M. E., Engeberg, S., McDowell, B. J., \& Burgio, K. L. (1992). Urinary incontinence: Why people do not seek help. Journal of Gerontologic Nursing, 18(4), 15-20.

Jolleys, J. V. (1988). Reported prevalence of urinary incontinence in women in a general practice. British Medical Journal, 296, 1300-1302.

Lagace, E. A., Hansen, W., \& Hickner, J. M. (1993). Prevalence and severity of urinary incontinence in ambulatory adults: An UPRNet study. Journal of Family Practice, 36(6), 610-614.

Norusis, Marija. (1994). SPSS Advanced Statistics 6.1. Chicago: SPSS Inc.

Nygaard, I., DeLancey, J., Arnsdorf, L., \& Murphy, E. (1990). Exercise and incontinence. Obstetrics \& Gynecology, 75(5), 848-851.

Sampselle, C. M., Burns, P., Dougherty, M., Thomas, K. K., Newman, D. K., \& Wyman, J. (1997). Continence for women: Evidence-based practice. Journal of Obstetric, Gynecologic, and Neonatal Nursing, 26, 375-385.

Sampselle, C. M., Wyman, J. F., Thomas, K. K., Newman, D. K., Gray, M., Dougherty, M., \& Burns, P.A. (2000). Continence for women: Evaluation of AWHONN's third research utilization project. Journal of Obstetric, Gynecologic, and Neonatal Nursing, 29, 9-17.

Samuelsson, E., Victor, A., \& Tibblin, G. (1997). A population study of urinary incontinence and nocturia among women aged 20-59 years. Prevalence, well-being and wish for treatment. Acta Obstetrica et Gynecologica Scandinavica, 76(1), 74-80.

Sommer, P., Bauer, T., Nielsen, K. K., Kristensen, G. G., Hermann, K. S., \& Nordling, J. (1990). Voiding patterns and prevalence of incontinence in women. A questionnaire survey. British Journal of Urology, 66(1), 12-15.

Thom, D. (1998). Variation in estimates of urinary incontinence prevalence in the community: Effects of differences in definition, population characteristics, and study type. Journal of the American Geriatric Society, 46(4), 473-480.

Carolyn M. Sampselle is a professor of nursing and women's studies and associate professor of obstetrics and gynecology, University of Michigan, School of Nursing in Ann Arbor.

Jean F. Wyman is a professor, Cora Meidl Siebl Chair in Nursing Research, at the University of Minnesota, School of Nursing in Minneapolis.

Karen Kelly Thomas is director of research, programs, and publications, Association of Women's Health, Obstetric and Neonatal Nurses, Washington, DC.

Diane K. Newman is an adult nurse practitioner, DKN \& Associates, Inc., Philadelphia, PA.

Mikel Gray is a nurse practitioner and associate professor, Department of Urology and School of Nursing, University of Virginia, Charlottesville.

Molly Dougherty is Frances Hill Fox Professor, Department of Community and Mental Health, University of North Carolina at Chapel Hill.

Patricia A. Burns is dean and professor, University of South Florida College of Nursing, Tampa.

Address for correspondence: Carolyn M. Sampselle, RNC, PhD, FAAN, University of Michigan, School of Nursing, 400 North Ingalls, Ann Arbor, MI 48109-0482. E-mail: csampsll@umich.edu. 